Etnográfica

Revista do Centro em Rede de Investigação em

Antropologia

vol. 19 (3) | 2015

Vol. 19 (3)

\title{
Estados posibles: travesías, ilegalismos y controles en la Triple Frontera
}

Estados possíveis: travessias, ilegalismos e controles na Tríplice Fronteira

\section{Brígida Renoldi}

\section{(2) OpenEdition \\ Journals}

Edición electrónica

URL: https://journals.openedition.org/etnografica/4049

DOI: 10.4000/etnografica.4049

ISSN: 2182-2891

\section{Editor}

Centro em Rede de Investigação em Antropologia

\section{Edición impresa}

Fecha de publicación: 1 octubre 2015

Paginación: 417-440

ISSN: 0873-6561

\section{Referencia electrónica}

Brígida Renoldi, «Estados posibles: travesías, ilegalismos y controles en la Triple Frontera», Etnográfica [En línea], vol. 19 (3) | 2015, Publicado el 27 octubre 2015, consultado el 10 febrero 2022. URL: http:// journals.openedition.org/etnografica/4049; DOI: https://doi.org/10.4000/etnografica.4049

\section{(c) (1) (8)}

Etnográfica is licensed under a Creative Commons Attribution-NonCommercial 4.0 International License. 


\section{Estados posibles: travesías, ilegalismos y controles en la Triple Frontera}

\section{Brígida Renoldi}

En este artículo describiré el movimiento de las personas que trabajan entre la legalidad y la ilegalidad, pasando mercadería ilegal, o legal sin realizar las declaraciones aduaneras, en la confluencia limítrofe de Brasil, Paraguay y Argentina. La noción de "ilegalismos" nos auxiliará en el análisis. El binomio legal/ilegal, explicitado en los códigos y reglamentaciones, produce una frontera moral entre lo aceptable y lo inaceptable desde el punto de vista del Estado. Al relatar las actividades que realizan estas personas y las condiciones en las cuales lo hacen se evidencian las tramas que borran tal frontera, así como las dinámicas en la vida cotidiana que van "haciendo" el estado en cada movimiento y decisión. Observar estos fenómenos desde la perspectiva nativa, de toda la red que liga cosas, espacios, personas, ámbitos y ambientes, permite reconocer que detrás de cada iniciativa existe una reformulación práctica de los términos ideales que definen el Estado. Esta perspectiva suspende los juicios que ven en la incongruencia entre lo que el Estado debería ser y lo que es el estado una falla sostenida en última instancia en la reificación del problemático dualismo de los conceptos de estado/sociedad, permitiéndonos reconocer los estados posibles.

PALABRAS-CLAVE: antropología del Estado, ilegalismos, Triple Frontera, travesía, contrabando, narcotráfico.

Estados possíveis: travessias, ilegalismos e controles na Tríplice Fronteira - Neste artigo descreverei o movimento das pessoas que trabalham entre a legalidade e a ilegalidade, passando mercadoria ilegal, ou legal, sem realizar os controles alfandegários, na confluência limítrofe de Brasil, Paraguai e Argentina. A noção de "ilegalismos" nos auxiliará na análise. O binômio legal/ilegal, explicitado nos códigos e regulamentações, produz uma fronteira moral entre o aceitável e o inaceitável do ponto de vista do Estado. Ao relatar as atividades que realizam estas pessoas e as condições nas quais o fazem se evidenciam as tramas que apagam tal fronteira, assim como as dinâmicas na vida cotidiana que vão "fazendo" o estado em cada movimento e decisão. Observar estes fenômenos da perspectiva nativa, de toda a rede que liga coisas, espaços, pessoas, âmbitos e ambientes, permite reconhecer que por trás de cada iniciativa existe uma reformulação prática dos termos ideais que definem o Estado. Essa perspectiva deixa em suspenso os juízos que veem na incongruência entre o que o Estado deveria ser e o que é o estado uma falha sustentada em última instância na reificação do problemático dualismo dos conceitos de estado/sociedade, permitindo-nos reconhecer os estados possíveis.

PALAVRAS-CHAVE: antropologia do Estado, ilegalismos, Tríplice Fronteira, travessia, contrabando, narcotráfico.

RENOLDI, Brígida (brire@hotmail.com) - Consejo Nacional de Investigaciones Científicas y Técnicas, Instituto de Estudios Sociales y Humanos, Universidad Nacional de Misiones, Argentina; Núcleo de Estudos em Cidadania, Conflito e Violência Urbana, Universidade Federal do Rio de Janeiro, Brasil. 


\section{CONTEXTO}

En este artículo narraré dinámicas humanas y mercantiles que se dan en la Triple Frontera de Argentina, Brasil y Paraguay. ${ }^{1}$ Busco reconstruir las lógicas nativas de quienes sortean sus vidas a través de emprendimientos diversos, pero también las del Estado y sus agentes a través de las legislaciones e intervenciones. La noción de "ilegalismos" operará como instrumento para contextualizar analíticamente el tránsito entre la legalidad y la ilegalidad que involucra a emprendedores y agentes. El desarrollo pretende evidenciar las formas de estado posibles que se generan en disidencia con los modelos formales, cuestionando y reinventando el orden gubernamental y administrativo local. ${ }^{2}$

En el año 2009 comencé a trabajar desde la perspectiva antropológica en esta frontera de tres ciudades unidas por ríos y puentes, de alrededor de 700 mil habitantes, que se caracteriza por una alta movilidad de personas y cosas, así como por el intercambio y flujo de mercancías. Se constituyó claramente en un foco de atención después de los atentados a la Embajada de Israel (1992) y a la Asociación Mutual Israelita Argentina-AMIA (1994) que fueron atribuidos en su momento a la comunidad sirio-libanesa residente en la región, sobre la que recayeron acusaciones de practicar y financiar el terrorismo. Posteriormente, al estallar las torres gemelas del World Trade Center (2001) se reforzaron sospechas en la misma dirección, que habilitaron detenciones en la zona de confluencia de los tres países (Amaral 2010).

Muchos de los sirio-libaneses desarrollan actividades comerciales en Ciudad del Este (Paraguay) desde que llegaron incentivados por la expansión de la región, propiciada en los años 70 por la construcción de la represa de Itaipú y por el estímulo comercial dado a partir de 1960 por el entonces presidente de Paraguay, Alfredo Stroessner. Además, una parte significativa de la población árabe, india y china, vive en Foz do Iguaçu y trabaja en Ciudad del Este, desplazándose todos los días en rutinas laborales (Rabossi 2007). Inclusive hay brasileños que migraron a Paraguay, conocidos como brasiguayos

I Agradezco a Piero Leirner, Ciméa Bevilaqua y Sabina Frederic el haber propiciado el debate "El estado, lo doméstico y lo político" en la XRAM, julio de 2013 (Córdoba, Argentina), en el que se inscribe la presentación que inspira este artículo. Mi gratitud es también hacia Miguel Carid, César Teixeira y Rolando Silla por las lúcidas lecturas de los borradores y generosos comentarios realizados.

2 Remitiéndome a la distinción planteada por Leirner (2012), utilizaré el término "Estado" para referirme al sistema administrativo que se presupone sobrepuesto al sistema de gobierno (Estado de derecho que funda la distinción entre lo legal y lo ilegal), tal como teóricamente ha sido definido por la sociología y la ciencia política, es decir, como modelo eficiente que contiene la política y la gestión. Por otro lado, utilizaré el término "estado" para referirme a las diferentes acciones llevadas a cabo por personas de carne y hueso y a las formas en que se dan los procesos de administración y gobierno, sin que necesariamente estas operen como dos caras de una misma moneda, sino como agencias que diluyen el dualismo estado/sociedad, para afirmar diferentes tipos de orden. Ver también Bevilaqua y Leirner (2000). 
(Albuquerque 2010), y comunidades indígenas que habitan y circulan por la frontera.

La progresiva vitalidad regional se dio también a partir de la creación del Mercado Común del Sur que en 1991 estimuló la dinámica comercial, al mismo tiempo que promovió algunas tensiones entre los países, en función de las desigualdades y particularidades de cada uno (Aguiar 2010). Estas se inscriben en el contexto del movimiento económico anclado en las iniciativas paraguayas para el libre comercio y en el uso de parte del territorio como ruta de transporte de drogas producidas en el país y provenientes de Bolivia, con destino a diferentes centros urbanos de la región. A pesar de la diversidad, las imágenes promovidas en buena medida por los medios de comunicación calificaron a la Triple Frontera como cuna de delitos económicos, de terrorismo y narcotráfico (Montenegro y Giménez Béliveau 2006; Rabossi 201 la).

Estos atributos no pasaron desapercibidos en el ámbito de las políticas públicas en los últimos años, sino que reforzaron las inversiones en seguridad, aumentando las acciones represivas y preventivas con énfasis en lo tecnológico (video-monitoreamiento, scanners, refuerzo de armas y municiones, e incremento de vehículos terrestres y vehículos aéreos no tripulados). A pesar de ello, las dinámicas locales evidencian que la población adopta diversos modos de organizarse para vivir, en los que combina actividades legales e ilegales, vínculos económicos, de parentesco y amistad, en redes transnacionales que hacen a la vida cotidiana local. En este contexto el papel del Estado, a través de las instituciones que controlan las fronteras, es significativo, tanto por lo que prohíbe como por lo que propicia con sus prohibiciones, dando lugar a múltiples "ilegalismos". Parto del término acuñado por Foucault (1986) para referirse a aquellas prácticas que se desarrollan en los intersticios legales (condenadas y viabilizadas al mismo tiempo por las formas y procedimientos legales). ${ }^{3}$ Entendiendo que la ley es un tipo de enunciación reglamentaria expresada desde la autoridad y legitimidad del Estado de derecho, y que la delincuencia es el conjunto de prácticas criminalizadas por el sistema judicial por ser disruptivas del orden dado por la vigencia de la ley, distinguiríamos aquí los ilegalismos como la combinación de acciones, objetos y decisiones que permiten esquivar el orden punitivo a partir de estrategias que no necesariamente están por fuera del dominio de los instrumentos legales. Pero, forzando un poco esta primera idea, podemos pensar los ilegalismos como las prácticas que crean cierta autonomía en la tirantez explícita con los bienes jurídicos tutelados por la ley. Disputan así diferentes órdenes que pueden no responder a los modelos defendidos por el Estado de derecho y, sin embargo, se sostienen en las tramas de la administración estatal, aunque no siempre

3 Una aproximación elucidativa al término "ilegalismo" fue realizada por Hirata (2014), quien rastrea la constitución progresiva del concepto en la obra de Foucault. 
exista la conciencia de que tales prácticas son punibles (pues pasan como favores, cuando alguien que debería reprimir facilita ciertas iniciativas, o simplemente como emprendimientos rentables). Comparto el principio de que deshacerse de los marcos analíticos que presuponen la existencia de errores que impiden alcanzar formas deseables de integración o desarrollo es posible adhiriendo al esfuerzo comprensivo a partir de abordajes etnográficos que contribuyan con la revisión de conceptos y paradigmas acerca del orden y del cambio (Telles 2009: 156; Heyman 1999; Herzfeld 1985; Ferguson e Gupta 2002; Gupta 1995).

En este sentido, evitaré calificar las prácticas a las que me refiero arriba con el término "corrupción" (que involucra a personas del ámbito público estatal en ilícitos) por considerarlo de naturaleza acusatoria desde la perspectiva del Estado, como bien lo señaló Misse (1999) al apuntar los riesgos de tomarlo por categoría analítica. Es importante señalar que la ley marca los límites desde el Estado tal como es formulado a partir de cierta visión teórica: es una referencia que divide el mundo en legal e ilegal. Sin embargo, a través de los ilegalismos las personas viabilizan sus formas de vivir. Ello puede ser visto como el resultado de iniciativas no legales que a veces se tejen con la administración estatal, y nos alerta sobre el hecho de que tal administración no responde siempre a los intereses explícitos defendidos por las leyes que ordenan el Estado. Antes que ver estas iniciativas como inadecuadas frente al modelo, o como degeneraciones que resultan de la invasión del crimen y el delito al interior del Estado, propongo observarlas como formas auténticas de los estados posibles. La evidente distancia entre el modelo y las tramas vitales puede alojar propuestas disidentes de las formas legales, y no necesariamente resistencias o luchas de poder con el Estado, desafiando aquello que separamos conceptualmente (adentro y afuera, Estado y sociedad). ${ }^{4}$ Toda la normatividad estatal es promovida a partir de cosas y de gente cuyas agencias pueden reorientar el curso formal previsto, aun dentro del propio orden administrativo y burocrático. En este tipo de intersticios se crean los estados posibles.

Por otro lado, muchos actos ilegales no son pensados como algo relacionado con la ley por quienes los practican, mientras otros deliberadamente lo son. Sin embargo, no siempre contribuyen con las altas esferas de poder o se ven favorecidos por ellas. Es aquí donde un comerciante de marihuana, o un "laranja" (aquella persona que ingresa mercaderías al Brasil sin declarar en la aduana), puede interrogar prácticamente los principios formales y morales del control estatal..$^{5}$ Inclusive porque el estado puede abrigar críticas

4 Latour (2004) ya observaba algo similar en su etnografía sobre el Consejo de Estado francés, al atender a las continuidades e hibridaciones entre los poderes de estado, a pesar de ser formalmente autónomos.

5 "Laranjas" normalmente hacen uso de su derecho a pasar mercadería por el valor de US\$ 300.00 por mes sin pagar impuestos de importación. Pero una vez registrados no pueden pasar de nuevo [continua] 
al Estado, agenciadas por personas que formalmente lo constituyen (Renoldi 2013a). ${ }^{6}$

En la frontera aquí relatada las mercancías circulan por los países de acuerdo a la conveniencia comparativa que presentan en diferentes momentos. Monedas, agroquímicos, drogas prohibidas, medicamentos, autopartes, transitan por tierra, por agua, o a través de los dos puentes que ligan las tres ciudades, en pequeña y mayor escala, legal e ilegalmente. Este movimiento está pautado por contextos que no dejan de poner en cuestión la validez y la legitimidad de los procedimientos de control y seguridad, tan evidentes como vulnerables, de los estados nacionales.

Se trata de una variedad de emprendimientos legales, informales e ilegales, que se reúnen en este espacio de concentración humana. A pesar de que desde el punto de vista estatal que define los códigos, leyes y medidas punitivas, algunos son vistos como indeseables y punibles, las personas que en carne y hueso habitan la frontera viven lo que hacen sin necesariamente inscribirlo en la clave de la ilegalidad, y menos aún reduciendo sus existencias a la dimensión mercadológica que los involucra en las prácticas económicas que colaboran con el sustento (Renoldi 2013a). Taussig, inspirado en Marx, ya afirmaba en 1980 que era preciso comprender el modo en que el sistema mercantil del capitalismo moderno engendraba una mentalidad mercadológica según la cual las personas tienden a ser vistas como mercancías y estas, a su vez, son concebidas como entidades animadas que dominan a las personas (Taussig 2010 [1980]: 52). "Laranjas", "paseros", "sacoleiros", "contrabandistas", "narcotraficantes", al fin y al cabo son términos que definen "identidades" por contacto. La condición de ilegalidad de las mercancías, o de sus modos de circular, se extiende a las personas que las tocan.

Podemos afirmar así que la distinción formal entre lo legal y lo ilegal carga un peso moral que merece ser atendido tomando precauciones epistemológicas y metodológicas. Me dedicaré en las próximas páginas a relatar experiencias y analizar el dominio de tal distinción para algunas personas que realizan actividades mercantiles, con el propósito de explicitar de qué manera personas, acciones, lugares y cosas ejercen su agencia en el curso de acontecimientos

hasta el mes siguiente, aunque lo hacen habitualmente corriendo el riesgo de que se les confisque la mercadería. En general trabajan para sus "patrones", que suelen ser "sacoleiros", quienes llevan las mercaderías a diferentes lugares de Brasil para revender en las calles, en pequeños circuitos, o a comerciantes medianos (Rabossi 2008).

6 Podrá objetarse a este análisis la ausencia de un tratamiento explícito del "poder" en sus dimensiones práctica y conceptual. Ello se debe, por un lado, a que las pistas para la inteligibilidad de las experiencias narradas aquí quizás no fueron tan claras en indicar la dimensión del "poder" al punto de permitir su descripción etnográfica. Por otro, optar por un abordaje teórico del "poder" tal vez hubiera derivado en una discusión diferente a la que los datos proponen, al menos en la clave de lectura que adopté. Esto no impide su exploración futura. 
específicos de esta frontera, condicionando y redefiniendo, así, el lugar y la naturaleza del estado.

\section{PASAR}

Atravesar el Puente de la Amistad durante el día para llegar desde Foz do Iguaçu a Ciudad del Este, en Paraguay, es un recorrido que a pesar de repetido me conmueve todas las veces que paso. Pasar. La palabra que en algún momento toda boca de un habitante de frontera exhala con una tranquilidad densa que un turista jamás llegará a experimentar. Con una cámara de fotos en la mochila, 80 reales en el bolsillo, un documento y un celular, adhería al ritmo de aquellos transeúntes que en fila india pasaban aquella mañana hacia "el otro lado". Un hombre se apura y acercándose me dice casi al oído con un acento entre argentino y paraguayo: "ojo, la mochila siempre adelante", alertándome sobre los hurtos al cargarla en la espalda. Pasa rápido y se pierde de mi vista con prisa. Traigo la mochila al frente mientras miro el río que emana una fuerza única, como si llamara. Un brasileño de unos 60 años, bajito y quemado por el sol, percibe mi fascinación y me dice: "Bonito, né? É lindo, é lindo!" "É", respondo, "dá vontade de cair na água". Dos segundos fueron suficientes para suponer que el hombre ya habría pasado más de una vez ese día, cargando peso, acelerando la marcha. El olor a sudor lo revelaba, y su ropa gastada y teñida de tierra colorada indicaba también que no era su hábito cambiarse tan seguido. Su torso, inclinado hacia adelante, iba como jugándole una carrera a sus pasos. Enseguida le pregunté si iba de compras, y no demoró en responder "sou laranja", presuponiendo que yo sabría que se trataba de las personas brasileñas que ganan su sustento transportando mercadería de un lado para el otro en pequeñas cantidades, sin registro aduanero, cobrando un monto por ese servicio. ${ }^{7}$ Quizás la curvatura algo diagonal de su espalda llevaba la memoria de la carga, variada pero regular, de tantos años de trabajo. En un portugués que ahorraba letras al finalizar las palabras me dijo que hacía tiempo que estaba difícil para pasar celulares, pero que era de lo que todavía se podía vivir: "Agora tá mai" difícil para mim trabalhar... a Receita tá atrapalhando muito e meu patrão já perdeu muita coisa já". ${ }^{8}$

Sin saber quién era yo, pero con el impulso de ser protagonista, me contó que hacía años se dedicaba a "pasar", primero cigarrillos, luego electrónicos, y también combinando unos y otros. Al hablar de los cambios ocurridos en la región desde que el gobierno brasileño puso rigor en sus controles fronterizos, comparaba con énfasis aquella buena época con el presente. No demoró en

7 Sobre el cotidiano de "laranjas" y "sacoleiros", ver Cardin (201 1, 2013) y Barros (2008).

8 "Ahora está más difícil para trabajar, la Receita está molestando mucho y mi patrón ya perdió bastantes cosas". 
referirse a que, como resultado de los riesgos recurrentes de pérdidas, ahora muchos patrones les cobraban las mercaderías perdidas a los "paseros" o "laranjas", o iban a medias en la pérdida, porque era común también que fueran asaltados por "piratas", sobre todo cuando se trataba de cargamentos mayores, y que en esos casos despertaban las sospechas de si se trataba realmente de robo, o de acuerdos entre transportista y ladrón. Situándose en un lugar diferenciado en este escenario aclaró que, como hacía tanto que trabajaba con la misma persona, ya existía la tranquilidad de que no sería él quien le robaría la mercadería. Pensé: es el tipo de confianza que llega a tornar la amistad un lazo semejante al de parentesco. Con su apuro me fue sacando ventaja y alcancé a desearle suerte cuando casi no me oía... hasta que se perdió en el tumulto que dándome las espaldas ingresaba a Paraguay.

En Ciudad del Este los vehículos se mueven con apuro, conteniendo la velocidad del acelerador bajo un pie que aprieta el freno. Como si estuvieran nerviosos presionan a los transeúntes al echárseles encima, empujándolos a paso de hombre, en una especie de competencia por el ámbito de circulación, creando un orden inexistente en los códigos de tránsito. Los puestos de mercaderías exhibidas en mesas definen la estética del lugar: ropas, zapatillas, anteojos, electrónicos, cosméticos, juguetes, aprisionados en veredas estrechas algo oscuras por los toldos y lonas que los protegen del sol. El establecimiento de los puestos de los "mesiteros" (mesas de venta en las veredas) responde a las negociaciones continuas que establecen con agentes de la municipalidad, por las que reformulan todo el tiempo las agencias ciudadanas y estatales (Rabossi 2008, 201 lb). Es una ciudad donde la espesura sonora está hecha de variedad de ruidos, de idiomas, risas, gritos, rugido de motores, cinta adhesiva que se despega y se pega como si fuera un ritmo musical propio, un mantra. Los olores: pollos fritos, mandioca, monóxido de carbono del humo de los coches; las formas coloridas de las chipas, ensaladas de frutas, el mate cocido, el tereré. Junto a eso, una sensación que acompaña a todo visitante: el estar muy alerta. Es un estado que combina la desconfianza con el temor y la osadía, sentimientos que se acentúan al llegar a la ciudad y que poco a poco se van disipando con la familiarización de los ritmos y sensaciones. Es la experiencia del extranjero, del forastero, que se detiene en determinado circuito espacial como emigrante potencial (Simmel 2012; Schütz 2012). Pero al observar a las personas que allí trabajan uno se da cuenta de que los estímulos que nos interpelan como foráneos parecen no ser tan exigentes para quien habita la ciudad, inclusive para los brasileños que todos los días van desde Foz do Iguaçu para atender sus comercios.

Las filas de motos presionan el puente de la Amistad hacia un lado y hacia el otro; valijas cargadas de cosas, carritos con pilas de paquetes, son arrastrados por las pasarelas en dirección a Brasil; colectivos llenos de cajas, equipajes, bolsas negras, bolsas de plástico con cierre, esperan el visto bueno en los controles 
aduaneros para poder seguir viaje en un ritmo contrario al de los corazones de algunos pasajeros que oran para que sus mercaderías no sean retenidas. Tal como lo describen Rabossi (2008) y Machado (2011), ya hubo períodos en que ese ritmo era muy ágil y respondía a la dinámica económica de importaciones y migraciones tramadas en la economía mundial. Actualmente cerca de 40 mil personas por día durante la semana visitan la ciudad con motivos turísticos y comerciales. A inicios de cada mes, cuando se cobran los sueldos, el flujo de gente aumenta porque muchos deciden hacer compras para uso personal. Algunos van por su propia cuenta en busca de lo que necesitan, mientras otros realizan sus pedidos a quienes se encargan de hacer la travesía.

El término "travesía" es utilizado con frecuencia por quienes realizan el pasaje internacional. La idea trae consigo la noción de ir de un lado a otro, más allá de los límites, afrontando desafíos. En este contexto los retos no son pocos. A veces, cuando van a hacer compras en su pleno derecho aduanero, les queda la sensación de que siempre algo puede estar mal hecho, y quedar así sujetos a interpelaciones al momento de atravesar aduanas y controles migratorios. Pero, en general, los temores son más frecuentes en aquellos que trabajan realizando el paso de mercadería que ingresará sin pagar los impuestos correspondientes a la importación, legalmente calificado como "contrabando".

Algunas fronteras suelen provocar ciertos temores porque son el ámbito físico, simbólico e icónico del Estado en su expresión de control y regulación. De hecho, la palabra "controles" es muy común en la jerga que predomina en estos espacios. En el paso que se traza entre Foz do Iguaçu y Ciudad del Este, el control establecido en la cabecera del Puente de la Amistad, del lado brasileño, cuenta con la Receita Federal (Administración de los Tributos Federales y Control Aduanero) y Migraciones, y la seguridad de las instalaciones y personas queda a cargo de la Policía Federal. Si bien estas agencias estatales están para controlar, no se observan intervenciones rigurosas en el flujo poblacional, poco o casi nada al ingresar a Paraguay y algo más, aunque variable, al ingresar de Paraguay a Brasil. En este caso el control es sobre todo de mercaderías y no tanto de documentos.

Por otro lado, el ingreso del lado paraguayo, si bien cuenta con una oficina de la Agrupación de Seguridad Urbana y Turística Nacional de Paraguay y con una oficina de Migraciones, la Aduana no aparece de manera ostensiva, y el trabajo que realizan es muy selectivo, principalmente para el ingreso de mercadería por importación en camiones. De modo general quien realiza el trámite migratorio lo hace porque sabe que circulando por el territorio brasileño o paraguayo, en un radio que exceda las ciudades de confluencia, puede ser multado al no portar los documentos obligatorios. Sin embargo, para aquellos que circulan en el lugar, estos registros no son exigidos.

Cuando las personas se refieren a la "travesía" ya anticipan todo lo que podrá acompañar el desplazamiento específico en esa frontera. Una travesía 
involucra a muchas personas que colaboran para hacerla posible; quien se dispone a "pasar" puede no conocerlas personalmente a todas, pero de ellas parte la información acerca de cuáles serán los lugares en que ocurrirán los controles y si habrá o no operativos reticulares a lo largo de las rutas. Este tipo de conocimiento se produce en los contactos establecidos, en la afirmación de relaciones de confianza que en algún punto de las redes conectan agentes policiales informados y población involucrada en las iniciativas. Si bien la figura del "informante" suele ser atribuida a aquella persona que ejerce el papel de espía para proveer información a la policía, no es raro que un rol semejante desempeñen en algunos casos agentes policiales para con aquellos que trabajan en esos circuitos. En términos sociológicos se trata de acuerdos reconocidos como formando parte del "mercado de protección", y el servicio en sí podría calificarse conceptualmente como "mercancía política", un recurso político que adquiere valor de cambio (Misse 2014; Pires 2014).

El acto de "pasar" descansa en algo más que una iniciativa, impulso o proyecto individual. Es un movimiento colectivo a través de pequeñas conexiones que van posibilitando su concreción. A las condiciones contextuales se suman factores librados a la "suerte". Por eso, muchas veces el haber tomado precauciones no garantiza que todo corra bien. Una situación inesperada que se interponga en su trayecto puede arruinarlo todo; no sólo el emprendimiento puntual, sino aquello que dependía de ese emprendimiento puntual. Si se trata de una pérdida de mercadería adquirida a partir de una cooperación de recursos, el responsable habrá tenido que dejar todo muy en claro con quienes realizaban sus inversiones (que podríamos considerar "apuestas" dada la incertidumbre sobre el resultado), y haber adquirido la confianza suficiente para que en caso de pérdida no se genere la sospecha de que pudo haber sido el mismo "laranja" que se dio a la fuga con la mercadería o con el dinero. En su defecto, hay que correr con los costos de la pérdida. Responder a este compromiso puede ocasionar lesiones irreversibles en los vínculos que hasta el momento funcionaban a modo de cooperación, ya que la imposibilidad o negativa a resarcir las pérdidas para el inversor no raramente trae como consecuencia la retaliación. Dependiendo del valor e importancia de la pérdida y de la confianza existente entre las partes, la medida puede oscilar entre el perdón, la ruptura total de ese vínculo mediante la interrupción de toda iniciativa conjunta, o la muerte del socio por venganza, a modo de ejemplo para los otros, y a la que en el ámbito policial y carcelario se refieren como una práctica regulada por la "ley del crimen".

De algún modo en este contexto se inscriben las rutinas de Rogeria, que viajaba los domingos durante toda la noche desde una ciudad del interior de Santa Catarina hacia Foz do Iguaçu. Dormía en el camino y se despertaba ya en la terminal de ómnibus, en cuyas proximidades vivía una amiga que se había hecho viaje tras viaje, de encontrarla en los comercios de Ciudad del 
Este, de hacer los mismos recorridos. Se hospedaba en su casa alguna que otra noche luego de hacer las compras en Ciudad del Este a lo largo del día, sobre todo si los controles estaban duros, para hacer tiempo y evitar perder la mercadería: "voy a esperar que baje el polvo", decía. Compraba celulares. En general viajaba en compañía de dos conocidos que se dedicaban a lo mismo y hacían juntos los circuitos de compras. Todos procedían de forma similar. Cuando retornaban, al subir al colectivo, guardaban parte de la mercadería en los espacios del techo correspondiente a su asiento, quitando con cuidado las placas para poder colocar los teléfonos y otros electrónicos pequeños. Si los controles de ruta paraban el colectivo y no había acuerdos con el chofer, todos los electro-electrónicos que se mezclaban con el equipaje podían ser incautados. Pero según algunos relataban, muchas veces los mismos agentes retienen parte de la mercadería y parte dejan circular.

Normalmente, Rogeria el mismo lunes volvía a Santa Catarina y dormía en el colectivo. Llegaba el martes, distribuía los teléfonos según los encargos y vendía aquellos que llevaba para aprovechar el viaje. En ese momento juntaba dinero para regresar a Foz y reponer la mercadería. Decía que le gustaba ver los billetes circulando, contarlos, sentirles ese olor único que solo la plata tiene, y en el comentario daba la impresión de que esa sensación le daba la fuerza para volver a emprender la "travesía" el mismo martes de noche. Saber que acumularía en cada viaje una diferencia que le permitiría pasar los períodos difíciles era el motor de todo aquel sacrificio mezclado con aventura. Ya había sido asaltada una vez durante un viaje de ida, en una ocasión en que tres personas interceptaron el colectivo, subieron al ómnibus y amenazando con armas a los pasajeros, muchos compradores, les sustrajeron el dinero. Además de la incautación de la mercadería por la policía están los riesgos de asaltos y "piratería" en las rutas. En los últimos años aumentaron los robos a vehículos de pasajeros compradores. El hecho de no llevar mercadería importada legalmente les quita el derecho a realizar denuncias por "piratería". Sin embargo, no es tan raro que habiendo sido víctimas de este tipo de acciones se dirijan individualmente a los policías explicando la situación. Este fue el caso por el que despidieron a algunos agentes de la policía municipal (Guarda Municipal) que se vieron involucrados en el secuestro de cigarrillos robados, de los cuales declararon una cantidad y el resto fue vendido a su dueño original, luego del pago de los valores pactados por interceder en el conflicto. Este tipo de acciones son vistas como justas por quienes sufren daños en esferas regidas por reglas que escapan al derecho oficial. Hay casos en que tanto del lado de los policías como del lado de los inversores se defiende la cooperación, y los instrumentos legítimos pasan a ser objeto de conquistas para parte de los involucrados (agentes, víctimas, aduana), en una especie de redistribución de beneficios y punición de hecho (en este caso la punición es 
para quien roba a los "contrabandistas", vistos como doblemente degradados) (Renoldi 2014).

Rogeria tenía más o menos 55 años, era una mujer delgada y jovial. Fumaba y vestía ropas modernas, zapatillas, jeans, remeras de algodón de colores vivaces. Transmitía también cierta masculinidad en su actitud, en sus gestos y formas de hablar, quizás necesaria para circular en esos ámbitos. Había sido madre soltera muy joven, pero sus hijos tempranamente abandonaron el hogar y dejaron de depender regularmente de ella. Se manejaba con autonomía; sabía ganar su dinero, generalmente de manera informal, se las rebuscaba, se "virava". Hacía más de veinte años que se dedicaba a pasar y revender electrónicos, conocía de memoria todo el circuito de ventas en Ciudad del Este y ya había visto a algunos comerciantes pasar del auge a la ruina en todo el vaivén de las economías mundiales y políticas regionales, sobre todo en períodos en que la Receita Federal apretaba más en Brasil, estrangulando el flujo de mercaderías entrantes de Paraguay, como comenzó a notarse a partir de 2004. Conocía muy bien las diferencias y potencialidades entre los aparatos que compraba. Afirmaba con seguridad total que había marcas desconocidas en el mercado que eran fabricadas por las grandes firmas, y que muchas veces sus capacidades no tenían diferencias sustantivas con los originales, pero sí en precio. Eso la llevaba a algunas hipótesis con relación al funcionamiento mercantil que la hacían sospechar de los procedimientos legales de las propias empresas.

Rogeria sabía que cada tanto una intervención rigurosa podía impedir el paso por el puente, y si la agarraba distraída corría riesgos económicos severos. Por eso tenía ya una red de contactos que sabía informarle cuánto tiempo durarían los controles, inclusive un taxista con el que trabajaba hacía años, que hablaba muy bien el portugués aunque era paraguayo, y que siempre estaba disponible cuando lo llamaba. Generalmente a través del mismo lugar que le proveía los teléfonos se enteraba de todo. El día que se tuvo que quedar dos noches en Foz esperando para pasar la mercadería del otro lado, habían instalado un puesto de la Força Nacional en el Puente de la Amistad, una unidad de seguridad compuesta por bomberos y policías militares provenientes de diferentes lugares del país que, en el contexto de la Estrategia Nacional de las Fronteras propulsada por el Ministerio de Justicia de Brasil, servía de apoyo a otras instancias de control fiscal y migratorio. En este caso daba apoyo a la Receita Federal, disponiendo agentes para realizar los controles de los vehículos colectivos y particulares, con personal y canes entrenados en el reconocimiento de drogas y municiones. Rogeria era lo que en Brasil se conoce con el nombre de "sacoleira", si bien de pequeña escala.

En el mirador del Puente Internacional de la Amistad, a menudo dos policías federales brasileños con sus fusiles a cuestas, observan el pasar de transeúntes y vehículos. Eventualmente saludan a alguien. Hablan entre ellos, usan 
sus celulares. De vez en cuando, con algo más que autoridad, revisan a los adolescentes que circulan por el puente, como si supieran de antemano que ocultan cosas, y raramente encuentran algo. Esta policía desarrolla tareas de investigación a través de agentes que circulan en busca de información conectando datos que les llegan por medio de denuncias y de rumores. No es raro que para abrir determinados canales de intervención tengan que hacer la "vista gorda" en algún informante involucrado en los mercados ilegales y redes.

El incremento de controles fronterizos que derivaron del desarrollo de la estrategia federal impactó en la dinámica de las actividades locales. ${ }^{9}$ Parte de las iniciativas gubernamentales consideró la articulación de diferentes instancias de control a partir de Gabinetes de Gestión Integrada municipales y de frontera que propiciaron el diálogo y el intercambio de informaciones a nivel institucional, así como la cooperación en las operaciones contra el tráfico de armas, de drogas y el contrabando. La vinculación de las diferentes fuerzas de seguridad (municipales, estaduales y federales) se encuentra en desarrollo desde 2012 y expresa un importante grado de consolidación en infraestructura, equipamientos, cooperación y acción, al mismo tiempo que evidencia algunas tensiones entre diferentes fuerzas de seguridad, desajuste de medidas a los contextos específicos de fronteras, e impactos asociados a la circulación de efectivos policiales ajenos a los cuadros locales que llegan con formación técnica y poca experiencia, sin tener vínculos in situ ni conocimiento de las dinámicas que prevalecen en el lugar. Sin embargo, el hecho físico de circular y de hacerlo atados a cosas y personas reconfigura necesaria y permanentemente las relaciones, sean entre pares o verticales dentro de las agencias estatales y también con el entorno.

Vale considerar que las personas que viven, transitan y usan esta frontera llevan cosas pero también son llevadas por cosas y afectos (Renoldi 2013a). En la distribución que las fuerzas motrices ejercen, a veces la acción promovida racionalmente no da cuenta de la infinidad de aspectos, materialidades y circunstancias que permiten o impiden la realización de un pasaje, un trayecto, una iniciativa. Ni posibilitan entender sus consecuencias. Si miramos estas acciones desde el punto de vista del Estado, diversas prácticas comunes en las fronteras internacionales estarán condenadas a la inmoralidad que las define como ilegales primero, e intencionales en dirección a herir la ley, después. Al ser pensadas como actividades apenas económicas que burlan el orden de Estado, reifican esferas que se vuelven prácticamente inasibles.

9 Un diagnóstico realizado a pedido de la Secretaría Nacional de Seguridad Pública de Brasil entre 2013-2014 por investigadores de la Universidad Federal de Rio de Janeiro, con colaboración de investigadores de todos los estados que componen la frontera brasileña, ofrece un panorama actualizado sobre el tema. 


\section{SOBRE EL ESTADO}

El estudio del Estado desde la perspectiva antropológica nos presenta siempre el desafío de tratar con, por lo menos, dos dimensiones empíricas definidas en torno a dos preguntas: ¿cómo se hacen las cosas en la vida cotidiana? y ¿̇ómo se imaginó que deberían hacerse, a partir de las pautas que componen las rutinas administrativas y gubernamentales estatales?

Esta observación pretende salir de la diferencia planteada entre lo que las personas "hacen" y lo que "dicen que hacen", muchas veces reducida en la interpretación de los científicos sociales a la dicotomía de "práctica" y "representación”, por la que la representación escondería las verdades de la práctica y que, a su vez, se muestran muchas veces a contrapelo de las pautas previstas como formas correctas y legítimas para el Estado, como si se configuraran en cierto modo en la desobediencia. ${ }^{10}$

Como resultado de una mirada no poco influenciada por las contribuciones de la ciencia política y de algunas asociaciones y divisiones derivadas de allí (Leirner 2012), durante algún tiempo las tendencias en el estudio de diferentes instancias del Estado pusieron el énfasis en el reconocimiento de las incongruencias que se daban entre cómo se hacían las cosas, cómo se decía que se hacían y cómo era esperable que se hicieran, asumiendo como especificidad de la aproximación científica el reconocimiento de las causas que no posibilitarían el real desarrollo de un pleno Estado de derecho.

En consecuencia, varios abordajes cayeron en declaraciones correctivas de los supuestos desvíos, a través de la crítica como elección metodológica, para convertirse en recurso de las políticas públicas. Estas, a su vez, descansando en una visión normativa, colaboraron reiteradamente con la reificación del concepto de estado y de las prácticas que toma como objeto de infinitas intervenciones, ajustes, correcciones e inclusiones, hasta en el caso de absorber en su propio seno aquello que considera por fuera de sí mismo, como sucede con el encarcelamiento. ${ }^{11}$ Se presupuso la sociedad por un lado y el Estado por otro, y se atendió a la relación establecida entre ellos, partiendo de la idea de que se trata de dos universos de fronteras y naturalezas definidas.

10 Una contribución reveladora sobre aspectos metodológicos y teóricos del quehacer antropológico puede encontrarse en Viveiros de Castro (2002), donde se pone en discusión el lugar que ocupan los dualismos a la hora de comprender la perspectiva de quienes pretendemos comprender. El autor presenta un orden de preocupaciones derivadas del, o que apuntan al, llamado giro ontológico, un movimiento epistemológico que asumido por la antropología sería capaz de reconceptualizar los mundos desde las perspectivas nativas, no ya como variaciones culturales de una naturaleza, sino como posiciones diferenciadas y relacionales en las continuidades y discontinuidades de mundos.

11 Las reflexiones de Clastres (2008) iluminan también este análisis, al enfatizar el modo en que fueron vistas las sociedades primitivas, siempre partiendo del entendimiento del Estado como la unidad de referencia englobante, deseable y necesaria. Ver también Viveiros de Castro (2008). 
Podríamos decir que en muchos casos los antropólogos y sociólogos adoptamos el punto de vista del Estado al analizar ciertas prácticas que circunscribimos de diferentes maneras a él, por ejemplo, cuando decidimos estudiar el contrabando, los inmigrantes clandestinos, el narcotráfico, categorías que conllevan sentidos claros de lo que sería correcto y aceptable, así como de aquello que se presenta como inadmisible y punible.

Pero los resultados de este abordaje son muy diferentes a los que obtendríamos si buscáramos reconstruir las teorías nativas que describen o explican el estado, desde dentro, por los mismos agentes, si lo pensamos como sistema administrativo, o desde fuera, si consideramos la población "delincuente" absorbida o en sus "márgenes", que define en cierto modo el corazón de la existencia del Estado: el monopolio de la fuerza y la prisión (Das e Poole 2004). ${ }^{12}$

Observar el Estado a partir del conjunto de prácticas, de historias, de burocracias, de casualidades y materialidades involucrados en cada decisión, cada acto, cada olvido, es comprender el estado como ejercicio y asumir el desafío de explicitar las teorías nativas sobre él, para hacerlas dialogar con las teorías sociales académicas actuales.

Pensando el Estado como modo de administración que prevé usos legítimos, entre ellos el de la fuerza pública, vemos que cada vez que nos remitimos a las redes que lo constituyen nos referimos, por ejemplo, a los procedimientos judiciales como la "justicia"; a la movilidad inter-fronteriza no declarada como "migraciones ilegales"; a las prácticas que desconsideran los códigos penales, dentro o fuera del estado, como "delitos y corrupción"; a la policía como "seguridad" y a la política como "representación".

$\mathrm{Y}$ al analizarlas bajo la luz de lo que se espera de un Estado pleno de derecho se derivan interpretaciones que a veces las califican como "arbitrarias", "clandestinas", "criminalmente organizadas" y "clientelares", evidenciando que el lugar desde el cual se están mirando estos objetos y relaciones no escapa a la intención reformatoria que defiende el modelo normalizador implícito en la idea de Estado como orden formal y legítimo, y en las leyes que lo garantizan (leyes que fundan el universo de la legalidad, frecuentemente sobrepuesto o confundido con el valor "justicia").

Este tipo de procedimiento interpretativo es más común de lo que imaginamos. En un artículo reciente, Jusionyte (2014) analiza un episodio ocurrido en Puerto Iguazú, una de las ciudades que componen la Triple Frontera. Un vehículo con inscripciones de los Bomberos Voluntarios había sido

12 Cunha (2014) revisa las discusiones en torno a los estudios sobre sistemas carcelarios, realizando interesantes precisiones acerca de los límites entre el adentro y el afuera en la práctica misma de encarcelar y vivir la prisión, precisiones que contribuyen con una reflexión metodológica próxima a la que nos ocupa en este artículo, sobre cómo estudiar el estado. 
utilizado para transportar marihuana en sus paneles, bajo la responsabilidad de un exbombero que aún colaboraba con las actividades de la institución, y había sido detenido a la altura de la ciudad de Corrientes, en la ruta 12 que conecta Iguazú con Buenos Aires. Este episodio lleva a la autora a proponer el concepto de "estado de camuflaje" para referirse a las prácticas ilícitas que se amparan en la apariencia estatal, en tanto performance y estética, para pasar desapercibidas o quedar protegidas. Si bien el relato alude al uso de las imágenes e instrumentos del Estado como forma de ocultamiento, el concepto de "camuflaje" pretende ir bastante más allá, en el sentido de atribuir a este tipo de comportamientos una especificidad que podría caracterizar una forma particular de Estado, justamente aquel que permite que se haga un uso performático de sí sustentando intereses particulares e ilícitos. Esto se conseguiría a través de la disipación de los límites entre un orden material o simbólico y otro (o sea, entre el gobierno y la delincuencia), definiendo así una forma específica de Estado (el estado como camuflaje de la delincuencia organizada), forma que resulta de la presencia del contrabando y de la corrupción como prácticas que impregnan las relaciones de esta frontera. De esta manera, la lógica del camuflaje mostraría cómo el Estado disfraza la violencia que concibe de forma separada a él, mientras posibilita las conexiones estéticas, pragmáticas y morales entre el arte de gobernar y la criminalidad (Jusionyte 2014: 116). Aunque su apreciación a partir del episodio no es completamente desacertada, tal vez contenga el equívoco de sobreponer las características descritas en el caso a las especificidades del estado en la frontera. Sin disentir con las evidencias, y considerando que se trata de una frontera con una reputación públicamente degradada, nos podemos preguntar si la aspiración a concepto del término, al estar sostenido en prácticas selectas, que la autora afirma estar extendidas en toda esta frontera, no contribuye con el efecto demonizador de la región. Los estados de camuflaje se multiplican en infinidad de prácticas ilícitas e ilegalismos que forman parte de diversas dinámicas urbanas de las cuales las fronteras son apenas una expresión, y la Triple Frontera en particular no escapa a este modus operandi, que es variado y se reproduce como manifestación de las formas de gobierno y de administración contemporáneas de gran parte de los países que han resultado de procesos de colonización. Entiendo que el concepto de "estado de camuflaje" encarna el mismo problema que el término "corrupción" y la mayoría de las expresiones que parten de las formulaciones estado-centradas. Ellos presuponen una forma de Estado que puede no ser la base de determinadas prácticas, y afirman dualismos basados en la noción de falsedad y verdad de los que se derivan, necesariamente, evaluaciones morales tendientes a preservar el punto de vista del Estado ideal, colocando las variaciones de formas como desvíos, enmascaramientos o degeneraciones de éste. El argumento que sostengo aquí no debe confundirse con lo que podría denominarse "apología del delito". Constato ciertas acciones en plena disputa 
por la legitimidad, y el caso del comercio de marihuana es una de ellas. A pesar de estar vedado por la legislación, este producto forma parte de la vida cotidiana de muchas personas, y los mercados se movilizan en función de nociones de "derechos" establecidas que pueden diferir en grados o completamente de aquello considerado como tal por el propio Estado (derecho a la información, que propicia la piratería; derecho a la tecnología, que propicia el contrabando de electro-electrónicos; derecho al menor costo, al vicio, al placer, por dar apenas algunos ejemplos).

Pensando en el hombre que en el relato inicial de este artículo se auto clasificaba como "laranja", consciente de que su trabajo era propiciar cierto tipo de comercio esquivando los controles aduaneros, de la misma manera que Rogeria al hacer sus travesías contando con la red de personas que le transmitían información sobre las características y duración de los controles, podemos pensar el estado como el conjunto de componentes híbridos, en el sentido dado por Latour (1991), que se hace de elementos (las cosas, mercaderías, trayectos), personas (compradores, vendedores, transportistas) y agencias (oportunidades, iniciativas, circunstancias, urgencias, demoras, esperas) en conexión, que operan en fronteras difusas y definen ámbitos de acción que desafían permanentemente el orden formal que provee y exige el Estado como universo de inclusión y definición de realidades. Es evidente al observar el trabajo de estas personas que el estado no tiene un límite, por más que se lo podamos atribuir al reconocer los dominios del aparato administrativo materializado en las oficinas, burocracias y espacios públicos, e incluso en las fronteras internacionales que miden el alcance de la soberanía. Si no tiene un límite, podríamos discutir la idea de margen, aunque en cierto modo sea operacional (Asad 2004). El estado se constituye en tramas de agentes y agencias no solo humanas, que en algún punto y momento se desprenden de la materialidad administrativa, proyectándose a otros universos de organización que a veces son funcionales a la propia dimensión administrativa, justamente por la determinación que muchas acciones informales pueden ejercer sobre la dimensión formal del Estado (Renoldi 2013b).

Viéndolo como un híbrido en este sentido, es interesante notar los esfuerzos que hacemos para darles nombres, definiciones, para diseccionarlos, digamos así, a partir de delimitaciones y conceptos que al marcar fronteras para crear entidades, tanto de cosas, personas y lugares, como de acciones y moralidades, afirman el Estado como valor único, además de legítimo y deseable. Esto ocurre cuando términos derivados de categorías jurídicas ("contrabandista", por ejemplo) operan provocando la adhesión de cierto tipo de prácticas a una definición criminal, lo que Misse llamó "sujeción criminal” y contiene un componente significativo de incriminación preventiva. Este procedimiento no es exclusivo del ámbito judicial o policial en sus manifestaciones formales de “incriminación”, sino que se extiende a diferentes ámbitos sociales que acaban 
tomando por referencia los tipos delictivos y precipitando juicios sin fundamento judicial, lo que Misse denominó "criminación” (Misse 2010). No caben dudas de que tales intervenciones generan definiciones de lo real con claras consecuencias epistemológicas.

\section{SOBRE LAS AGENCIAS}

En el abordaje etnográfico de diferentes instancias estatales, como ya dije, noté que observar el estado es algo más que mirar la burocracia, aunque esta sea crucial para el Estado. Al ver a las personas desarrollando sus tareas, en ellas pude identificar prácticas específicas y ambiguas, así como fronteras móviles entre los poderes que componen el Estado. O sea, donde se afirma la separación taxativa entre el poder judicial y el ejecutivo, como instancias administrativas y de gestión, la continuidad que se establece en el tránsito de las personas, a través de cosas y mensajes que llevan y traen, opera conectando otras personas y cosas, y forja significados que se tejen justamente en la difusión de estos espacios y ámbitos definidos como separados teóricamente (Renoldi 2010). Aunque en principio esto parecería un defecto, bien puede ser pensado desde otros ángulos, inclusive como propiedad. No adoptaría el término "camuflaje" desde el momento en que presupone algo que oculta otra cosa, y ese algo que disfraza es concebido como un real corrompido y corregible. Los "híbridos"13 resultantes son reales; concebir como teatrales (o parodias) las experiencias y expresiones que revelan las etnografías solo ayuda a reificar moralidades que encarnan los principios del Estado como naturalmente buenos. Reitero que el objetivo del abordaje defendido aquí es liberarse de cuestiones y demandas orientadas por los esfuerzos de intervención o de reforma social (Barbosa y Renoldi 2013).

El curso de agencias múltiples que van configurando estos fenómenos de circulación, ilegalismos, protección y controles se materializa en sentencias, deportaciones, políticas públicas, comercio, multas, prisiones, residencias, emprendimientos, olvidos, arquitecturas e ingenierías... puentes, por ejemplo, que a su vez promueven otras cosas, como conexiones, pausas, estrategias, ritmos, estadísticas, evasiones.

Todo lo que sucede produce algún orden provisorio, y es en este punto que se hace difícil la gestión de la política pública, cuando una medida de gobierno se plantea en términos de intervención racional y estratégica, en un universo

13 El concepto de "híbrido", a pesar de que el término en su etimología nos remite a entidades puras que se cruzan, se propone como un complejo en movimiento. Según Latour (1991), las entidades concebidas como puras son resultado de procesos de purificación occidental (la "naturaleza”, por ejemplo), pues en el principio todo es híbrido, compuesto de diferencias que se someten a selectividades homogeneizantes para volver a mezclarse. 
que fue diagnosticado y configurado como problemático al establecer la relación entre aquello que la ley prohíbe y las formas en que las personas viven. De este modo, volviendo a nuestro referente empírico original, una intervención estatal que presupone un "contrabandista", jamás podrá regular ni resolver las cuestiones que la vida le presenta a un "laranja". Hay una dimensión que la primera categoría omite, relacionada a valores, a las fuentes de sustento, a formas de vida, al trabajo, ${ }^{14}$ al enfatizar la transgresión legal; mientras la otra, "laranja", circunscribe semánticamente la actividad al mundo más amplio de la vida.

Experiencias que viví en diferentes ámbitos de la frontera fueron revelando que donde uno anhela la separación aséptica entre el Estado y la sociedad encuentra tramadas redes de confianza basadas en la amistad, el parentesco o las asociaciones, que constituyen ámbitos difusos a partir de relaciones humanas y objetales que hacen variar sus extensiones, repliegues y límites. ¿Qué papel juega en la configuración de las prácticas concretas el modelo que presupone un Estado y una sociedad pre-existentes que entran en relación? ¿De qué manera en el ejercicio cotidiano se crean "formas posibles" de estado que pueden entrar en tensión con las "formas previstas" de Estado, poniendo en evidencia el hecho de que las instancias de administración no necesariamente son regidas por las iniciativas de gobierno supuestas en los procesos formales de representación política? Las personas van creando intereses y usos divergentes de los modelos a los que adhieren voluntariamente a través del voto que las representa.

Nos es útil aquí una observación metodológica de Das, por la que nos invita a estudiar el estado a partir de un desplazamiento de la mirada que solemos echar sobre los lugares obvios en los que se supone que reside el poder, hacia los márgenes y recovecos de la vida cotidiana en la que los infortunios se vuelven observables (Das 2007: 164). Para hacer etnografía en las fronteras de lo legal y de lo ilegal, de las ilegalidades y de los ilegalismos, es necesario suspender el calificativo de "ilegitimidad" de determinadas prácticas para poder atender a las razones, los motivos de sus permanencias y las justificaciones dadas por las propias personas que hacen el estado día a día. Esto se torna evidente, por ejemplo, al observar la distinción entre la policía y el policía, y la distinción entre el "contrabandista" y el "laranja", "pasero" o "sacoleiro". Entre la policía y el "contrabando" no hay arreglo, porque ellos pertenecen al mundo del Estado, pero sí entre el policía y el "laranja", el policía no es la policía, así como el "laranja" no es el "contrabandista". Como vemos, esta distinción

14 Muchas personas que viven de estas actividades se refieren a sus ocupaciones como "trabajo", una categoría que también discute perspectivas, aspectos formales e informales, legales e ilegales. Sin embargo, no es infrecuente la tendencia a evitar su uso desde las ciencias sociales y a reemplazarlo por "actividades, emprendimientos o prácticas", cuando se inscriben en la dimensión informal o ilegal. 
engloba puntos de vista que son, rigurosamente, perspectivas, posiciones en el mundo, y no apenas miradas sobre él. Son agencias mundanas.

El concepto de agencia, entendido como aquella capacidad de las personas y objetos de iniciar secuencias causales, de hacer que las cosas ocurran, tal como sostiene Gell (1998) en su análisis semiótico del arte, nos daría la posibilidad de entender las configuraciones a las que me remito. Al contrario de interpretarlas como errores, la idea de agencia nos permite comprender cómo se hace el estado en lo cotidiano, reconocer la complejidad de las teorías nativas en diferentes ámbitos e identificar en ellas los procesos de invención y convención que señala Wagner (1975) como constitutivos de la cultura (en tanto herramienta y resultado), lo que nos desafía a pensar desde otro lugar un universo que solemos cosificar a través de categorías y conceptos disciplinares y estado-céntricos.

\section{CONEXIONES DE CIERRE}

Diferentes situaciones que se me presentaron en el trabajo de campo en la frontera tri-nacional, con población que vive y circula y con agentes de seguridad, me llevaron a repensar cómo determinadas cuestiones, principalmente las iniciativas económicas, se vuelven "problemas" para el Estado, a la vez que las medidas que éste asume van abriendo cadenas de consecuencias, reconfigurando escenarios en los que las personas, las políticas y la tecnología se cruzan y se inter-determinan creando otros problemas.

Como aclaré al principio, la Triple Frontera es señalada por los ámbitos estatales de seguridad y justicia de Argentina y Brasil como la cuna regional del terrorismo, del contrabando y del tráfico de drogas: "es zona caliente de narcotráfico", suelen decir en Argentina. La categoría "narcotráfico", al igual que otras ya mencionadas aquí, a pesar de no ser estrictamente jurídica, posee una carga moral que se expande en derivaciones "criminantes", en el sentido del efecto de "criminación" enunciado más arriba por el cual términos que se remiten a categorías criminalizantes, y que pueden derivar en incriminaciones, son apropiados por discursos públicos que se expanden, como expresiones acusatorias, estigmatizantes y objetualizantes (narcocriminalidad, narcocultura, narconegocios, narcos, narcoestados, narcolavado, por nombrar solo algunos). De este efecto no escapa el universo de adjetivos específicos que le son atribuidos a la Triple Frontera. En el caso de las drogas, la perplejidad que deviene al comprobar los modus operandi de "camuflaje", tal como Jusionyte (2014) lo describe, está anclada en una pregunta ausente acerca del orden legislativo y de la política de drogas, que nos sitúa frente a estas prácticas evaluándolas como desvíos inadmisibles, mientras omite el reconocimiento de la existencia de un mercado de producción y consumo activo con relación a la marihuana y otras substancias, que los gobiernos, legislaciones y economías mundiales, insisten 
en reprimir (puesto que no se trata de regular, sino de extirpar haciendo caso omiso de la numerosa población que a lo largo de la historia ha optado por prácticas similares y se ha expuesto a las políticas inhumanas represivas, de contaminación ambiental y de exterminio de gente). Es para tornar más explícito el argumento que tomo aquí el caso de las drogas ilícitas, cuya circulación y comercio se inscribe en dinámicas más generales económicas y sociales que caracterizan no solo la frontera. El caso evidencia el modo en que las condiciones y elecciones de vivir y habitar configuran posibilidades de orden a través de los ilegalismos, y se tensionan con los modelos, inclusive desde dentro de las instituciones previstas para reprimir.

La distinción entre lo legal y lo ilegal, tratándose de mercancías, está anclada de manera muy clara en los controles mercantiles y, por supuesto, generará siempre un universo de persecuciones, evasiones y capturas. Formulada desde el punto de vista del Estado esta distinción produce una división radical, por la que lo ilegal se presenta como una ruptura con el mundo legal. A ello hay que sumarle la carga de valores morales positivos a lo legal, y negativos a lo ilegal, y la consecuente generación, por medio de procedimientos metonímicos, de la clasificación de personas en legales e ilegales: ciudadanos y delincuentes. Son binarismos que esconden las tramas en las que las responsabilidades son colectivas. El concepto de ilegalismos viene aquí a operar como una herramienta para visualizar el universo de posibilidades dadas en el movimiento real entre lo legal y lo ilegal, como acciones creativas y, en cierto modo, también alternativas.

Los productos legales que pasan la frontera sin pagar impuestos (electro-electrónicos, vestimenta), así como los productos de circulación ilegal (cigarrillos, agroquímicos) y aquellos ilegales en sí mismos (drogas, medicamentos falsificados, juguetes y alimentos adulterados), se sostienen en redes variables asentadas en rutinas concisas y en su reiteración sobre la base de acuerdos y confianza que van moldando el estado en función de iniciativas no previstas por sus legislaciones, pero que al final de cuentas no dejan de definirlo. Dándole su debida importancia al riesgo que conllevan los productos de calidad dudosa, aunque proporcionalmente no adquieran la magnitud que el resto de las mercancías circulantes, pondría el énfasis aquí en la ampliación del margen de consumidores que accede a productos que de otra manera serían inasequibles. Este fenómeno se vería reflejado en lo que Lins Ribeiro llamó "economía popular global", como la globalización de abajo que permite el acceso a flujos de riqueza global en movimientos paralelos (Ribeiro 2009: 24). Tal vez el término "popular" no sea el más operativo, precisamente por remitir a una masa universal de personas predeterminadas y reconocidas apenas por una condición de clase. De la misma forma, el atributo de paralelismo presupone un tipo de economía que en algún punto se desprende de otra economía, cuando las etnografías utilizadas sugieren que no se trata de procesos separados (inclusive 
el autor lo nota, aunque no desiste del uso del término). A pesar del fenómeno que el concepto de economía popular global pretende retratar, quizás todavía peque, al igual que el abordaje de Jusionyte, de tomar por referencia universos ideales en base a los cuales se utilizan términos cargados de valoraciones que terminan reproduciendo la epistemología estatal, tal como se percibe en la simplificación a la que cede el autor en el siguiente párrafo:

"La globalización económica no hegemónica está estructurada por diferentes tipos de segmentos y redes que se juntan en un patrón piramidal. En la cima hallamos confabulaciones de lavado de dinero, actividades mafiosas y toda suerte de corrupción. A pesar de todo el poder y de la posición elitista de muchos de los agentes involucrados en la economía global paralela, ellos no pueden actuar solos" (Ribeiro 2009: 24, énfasis mío).

En el universo de relaciones de las cuales los aspectos económicos definen apenas una parte de la vida de las personas en la frontera que observamos hasta aquí, las categorías legal e ilegal que sostienen la epistemología estatal pueden disolverse en otra cosa a partir de los movimientos que las personas hacen, de las relaciones que establecen, de los acuerdos alcanzados y de los conflictos que pueden derivar de la intensidad de los intercambios. En cada gesto que desatiende tal distinción, otro tipo de orden es accionado, y otras formas son imaginadas. Descarto la opción de pensarlas simplemente como desobediencias, camuflajes, desviaciones o paralelismos, y admito la fuerza que esas formas de vida y elecciones adquieren cuando cada agente, sea estatal o no, en algún punto se pregunta y redefine con sus actos qué es el estado. Esta fuerza es continua, pero no para corroer el Estado, sino para "hacer" el estado en otras formas posibles, reutilizando elementos y creando artefactos que hasta podrían potencialmente reformularlo por completo.

Pensando en el contexto trinacional al que se refiere este artículo, podemos decir que cuando la frontera pasa de ser un límite a ser un recurso, cuestionando en todo uso particular los propios principios que rigen el Estado de cada país, nos vemos obligados a mirar en otra clave. Dependiendo de la perspectiva, el "contrabando" puede ser visto sólo como comercio y el "inmigrante clandestino" alguien que va apenas en busca de oportunidades, tal como Rabossi $(2008,201$ lb) lo muestra al etnografiar el comercio en Ciudad del Este en términos de emprendimiento cotidiano que debe gestionar márgenes de legalidad y de oportunidad para la subsistencia, y como lo hace también De Genova (2002) al proponer un abordaje histórico de los procesos políticos de ilegalización que producen la migración, algo más complejo que vaya más allá de la mera ilegalidad de los migrantes indocumentados. Este tipo de lectura propone una mirada reflexiva que atiende a lo que las mismas políticas públicas producen: fenómenos objetivados, externos al Estado. Como efecto 
político-epistemológico no asumido, se imponen la obligación de aniquilar aquello mismo que inventaron.

La Triple Frontera, descrita y considerada aquí bajo ciertos aspectos, pone en evidencia las tramas que la constituyen, y que nos invitan a mirar más allá de las claves legal, económica y también política (en el sentido de relaciones de poder, fuerzas y control) que atraviesan la vida de las personas. Inclusive nos interpela a revisar nuestros puntos de partida como investigadores y analistas.

Quizás haya más urdimbres que lógicas separadas, urdimbres que con seguridad se distancian de los modelos teóricos de Estado que defendemos con nuestros sistemas oficiales de representación. En ellas no es tan fácil separar una cosa de otra, y lo notamos al acompañar tanto personas como mercancías en los trayectos que hacen y en las formas en que los hacen. Habrá que preguntarse entonces si la distribución moral de mal y bien para crimen y Estado no es una división más que opaca la comprensión, desde dentro, de los estados posibles.

\section{BIBLIOGRAFIA}

AGUIAR, José Carlos, 2010, Stretching the Border: Smuggling Practices and the Control of Illegality in South America. Santiago, Global Consortium on Security Transformation (GCST), New Voices Series, 6, disponible en < http://hdl.handle.net/1887/17996> (última consulta en septiembre 2015).

ALBUQUerQue, Lindomar, 2010, A Dinâmica das Fronteiras: Os Brasiguaios na Fronteira entre o Brasil e o Paraguai. São Paulo, Annablume.

AMARAL, Arthur Bernardes do, 2010, A Tríplice Fronteira e a Guerra ao Terror. Rio de Janeiro, Apicuri.

ASAD, Talal, 2004, "Where are the margins of the State?", en V. Das e D. Poole (orgs.), Anthropology in the Margins of the State. Santa Fe, SAR Press, 279-288.

BARBOSA, Antônio Rafael, e Brígida RENOLDI, 2013, "Introdução", en Antônio Rafael Barbosa, Brígida Renoldi y Verissimo Marcos (orgs.), (I)Legal: Etnografias em Uma Fronteira Difusa. Rio de Janeiro, Editora da Universidade Federal Fluminense, 11-22.

BARROS, Adriane, 2008, "A informalidade dos laranjas na fronteira Brasil/Paraguai", História na Fronteira, 1 (1): 61-88.

BEVILAQUA, Ciméa, e Piero LEIRNER, 2000, "Notas sobre a análise antropológica de setores do Estado brasileiro", Revista de Antropologia, 43 (2): 105-140.

CARDIN, Eric, 201 1, Expansão do Capital e as Dinâmicas da Fronteira. São Paulo, Universidade Estadual Paulista Júlio de Mesquita Filho.

CARDIN, Eric, 2013, "La historia de una vida en situación de frontera", Revista de Estudios Sociales, 48: 100-109. 
CASTRO, Eduardo Viveiros de, 2002, "O nativo relativo", Mana: Estudos de Antropologia Social, 8 (1): 113-148.

CASTRO, Eduardo Viveiros de, 2008, "Uma boa política é aquela que multiplica os possíveis", entrevista realizada por Renato Sztutman y Stelio Marras, en Renato Sztutman (org.), Encontros: Eduardo Viveiros de Castro. Rio de Janeiro, Beco do Azougue, 228-259.

CLASTRES, Pierre, 2008, La Sociedad contra el Estado. La Plata, Terramar.

CUNHA, Manuela, 2014, "The ethnography of prisons and penal confinement", Annual Review of Anthropology, 43: 217-233.

DAS, Veena, 2007, "The signature of the state: the paradox of illegibility", en V. Das, Life and Words: Violence and the Descent into the Ordinary. Berkeley y Los Angeles, University of California Press, 162-183.

DAS, Veena, y Deborah POOLE (orgs.), 2004, Anthropology in the Margins of the State. Santa Fe, SAR Press, 3-33.

DE GENOVA, Nicholas, 2002, "Migrant 'illegality' and deportability in everyday life", Annual Review of Anthropology, 31: 419-447.

FERGUSON, James, y Akhil GUPTA, 2002, "Spatializing states: toward an ethnography of neoliberal governmentality", American Ethnologist, 29 (4): $981-1002$.

FOUCAULT, Michel, 1986, Vigilar y Castigar. Madrid, Siglo XXI.

GELL, Alfred, 1998, Art and Agency: An Anthropological Theory. Oxford, Clarendon Press.

GUPTA, Akhil, 1995, "Blurred boundaries: the discourse of corruption, the culture of politics, and the imagined state", American Ethnologist, 22 (2): 375-402.

HERZFELD, Michael, 1985, The Poetics of Manhood: Contest and Identity in a Cretan Mountain Village. Princeton, Princeton University Press.

HEYMAN, Josiah M. (org.), 1999, States and Illegal Practices. Oxford y Nueva York, Berg.

HIRATA, Daniel, 2014, “Ilegalismos”, en José Luiz Ratton, Renato Sérgio Lima y Rodrigo Ghiringhelli de Azevedo (orgs.), Crime, Polícia e Justiça no Brasil. São Paulo, Contexto, 97-104.

JUSIONYTE, Ieva, 2014, "States of camouflage", Cultural Anthropology, 30 (1): 113-138.

LATOUR, Bruno, 1991, Nous n’avons jamais été modernes: Essai d'anthropologie symétrique. París, La Découverte.

LATOUR, Bruno, 2004, La fabrique du droit, une ethnographie du Conseil d'Etat. París, La Découverte.

LEIRNER, Piero, 2012, "O Estado como fazenda de domesticação", Revista de Antropologia da UFSCar, 4 (2): 38-70.

MACHADO, Rosana Pinheiro, 201 1, Made in China: (In)Formalidade, Pirataria e Redes Sociais na Rota China-Paraguai-Brasil. São Paulo, Hucitec.

MISSE, Michel, 1999, Malandros, Marginais e Vagabundos: A Acumulação Social da Violência no Rio de Janeiro. Rio de Janeiro, IUPERJ, tesis doctoral.

MISSE, Michel, 2010, "Crime, sujeito e sujeição criminal: aspectos de uma contribuição analítica sobre a categoria 'bandido', Lua Nova, 79: 15-38.

MISSE, Michel, 2014, "Mercadorias políticas" y "Sujeição criminal”, en José Luiz Ratton, Renato Sérgio Lima y Rodrigo Ghiringhelli de Azevedo (orgs.), Crime, Polícia e Justiça no Brasil. São Paulo, Contexto, 198-212.

MONTENEGRO, Silvia, y Verónica GIMÉNEZ BÉLIVEAU, 2006, La Triple Frontera: Globalización y Construccion Social del Espacio. Buenos Aires, Miño y Dávila. 
PIRES, Lenin, 2014, "Mercados informais e economia popular: possíveis fronteiras entre moralidades e legalidade nas relações da sociedade e o estado", en César Barreira, Jânia Aquino y Leonardo Sá (orgs.), Violência, Ilegalismos e Lugares Morais. Campinas, Pontes de Campinas, 325-340.

RABOSSI, Fernando, 2007, “Árabes e muçulmanos em Foz do Iguaçu e Ciudad del Este: notas para uma re-interpretação", en Giralda Seyferth et al. (orgs.) Mundos em Movimento: Ensaios sobre Migrações. Santa Maria, Editora UFSM, 287-312.

RABOSSI, Fernando, 2008, En las Calles de Ciudad del Este: Una Etnografía del Comercio de Frontera. Asunción, Centro de Estudios Antropológicos de la Universidad Católica.

RABOSSI, Fernando, 2011 a, “Como pensamos a Tríplice Fronteira?”, en Lorenzo Macagno, Silvia Montenegro y Verónica Giménez Béliveau (orgs.), A Tríplice Fronteira: Espaços Nacionais e Dinâmicas Locais. Curitiba, Editora UFPR, 39-61.

RABOSSI, Fernando, 201 lb, "Negociações, associações e monopólios: a política da rua em Ciudad del Este (Paraguai)", Etnográfica, 15 (1): 83-107.

RENOLDI, Brígida, 2010, "As continuidades do descontínuo: o trabalho policial e judicial em casos de narcotráfico na fronteira da Argentina com o Paraguai", Antropolitica, 28: 197-220.

RENOLDI, Brígida, 2013a, "Fronteras que caminan: relaciones y movimiento en la frontera tripartita de Argentina, Paraguay y Brasil", Revista Transporte y Territorio, 9: 123-140.

RENOLDI, Brígida, 2013b, Carne de Carátula: Experiencias Etnográficas de Investigación, Juzgamiento y Narcotráfico. La Plata, Al Margen.

RENOLDI, Brígida, 2014, "Organización, crimen y acción: relatos policiales de la Triple Frontera”, en César Barreira, Jânia Aquino y Leonardo Sá (orgs.), Violência, Ilegalismos e Lugares Morais. Campinas, Pontes de Campinas, 479-507.

RIBEIRO, Gustavo Lins, 2009, Otras Globalizaciones: Procesos y Agentes Alter-Nativos Transnacionales. Brasília, Editora da Universidade de Brasília.

SCHÜTZ, Alfred, 2012, "El forastero: ensayo de psicología social", en Georg Simmel et al., El Extranjero: Sociología del Extraño. Madrid, Ediciones Sequitur, 21-26.

SIMMEL, Georg, 2012, "El extranjero", en Georg Simmel et al., El Extranjero: Sociología del Extraño. Madrid, Sequitur, 27-42.

TAUSSIG, Michel, 2010 [1980], O Diabo e o Fetichismo da Mercadoria na América do Sul. São Paulo, UNESP.

TELLES, Vera da Silva, 2009, "Ilegalismos urbanos e a cidade", Novos Estudos (CEBRAP), 84: 153-173.

WAGNER, Roy, 1975, The Invention of Culture. Chicago, The University of Chicago Press. 